\title{
Assessment of Knowledge, Attitude and Practice Toward Emergency Contraceptive Among Females Student at Unity University, Adama Town, Oromia Regional State, Ethiopia
}

\author{
Abenet Menene ${ }^{1, ~}$, Addisalem Getachew ${ }^{2}$, Aliye Kediro ${ }^{1}$, Bekele Gutema ${ }^{3}$ \\ ${ }^{1}$ Department of Nursing, College of Health Sciences, Arsi University, Asella, Ethiopia \\ ${ }^{2}$ St. Paulo's Hospital and Medical College, Addis Ababa, Ethiopia \\ ${ }^{3}$ Department of Laboratory, College of Health Sciences, Arsi University, Asella, Ethiopia
}

\section{Email address:}

abenetmen@gmail.com (A. Menene), adisgetachew85@gmail.com (A. Getachew), aliyekediro@yahoo.com (A. Kediro), bekishgutema@yahoo.com (B. Gutema)

${ }^{*}$ Corresponding author

\section{To cite this article:}

Abenet Menene, Addisalem Getachew, Aliye Kediro, Bekele Gutema. Assessment of Knowledge, Attitude and Practice Toward Emergency Contraceptive Among Females Student at Unity University, Adama Town, Oromia Regional State, Ethiopia. International Journal of Clinical and Experimental Medical Sciences. Vol. 6, No. 5, 2020, pp. 96-103. doi: 10.11648/j.ijcems.20200605.13

Received: August 24, 2020; Accepted: September 9, 2020; Published: November 23, 2020

\begin{abstract}
Background: Unwanted teenage pregnancies have a notable detrimental impact on the learners' trajectory and have been associated with jeopardizing the students' educational progress and future career prospects. These pregnancies are mostly unplanned and unintended and many are terminated, either legally or illegally. Each year, about 210 million women around the world become pregnant. Among them, about 75 million pregnancies (36\%) are unplanned and/or unwanted. Globally, more than 20 million women experience ill health as a result of pregnancy each year. Objective: To assess knowledge, attitude and practice towards emergency contraceptive methods among female students in Unity University, Adama, Oromia, Ethiopia, 2019. Methods: A Cross-sectional quantitative study was conducted among 276 Unity University undergraduate students. Self-administered questionnaire was used to collect the desired sample size. Study participants were selected by stratified random sampling, stratify based on year and department in the study. Data entry was done by using Epi Info and analysis was done by using SPSS version 21. Data was presented by tables, figures, diagrams. Result: The response rate was $100 \%(\mathrm{n}=276)$, out of which 259 (93.8) where within the age category of 15-24 and 17 (6.2) of them are within the age category of 25-29. 159 (72.4\%) of the respondents had good knowledge on Emergency contraceptive (EC). More than half (69.7\%) of them had positive attitude towards Emergency contraceptive. Of the Respondents 75 (27.5\%) were experienced sexual intercourse out of them 55 (20.4\%) were used Emergency contraceptive. Conclusion: overall awareness of EC was very high among female students at the Unity University, more than half had good knowledge of EC and majority of them had a positive attitude towards using EC. Use of EC was low and half of those who were pregnant reported that the pregnancy was unintended.
\end{abstract}

Keywords: Knowledge, Attitude, Practice, Emergency Contraceptive, Ethiopia

\section{Introduction}

Emergency contraception (EC) is a type of modern contraception which is indicated after unprotected sexual intercourse when regular contraception is not in use or sexual assault [1]. Each year there are about 250 Million pregnancies globally and one third of these are unintended and $20 \%$ of these undergo induced abortion. In Low income countries, more than one third of the 182 million pregnancies are unintended; the fate of $19 \%$ will be induced abortion and $11 \%$ of this is unsafe [2].

The proportion of women aged 15-19 years in Africa who have had an unsafe abortion is higher than in any other region; almost $60 \%$ of unsafe abortions in Africa are among women 
aged less than 25 years and almost $80 \%$ are among women below age 30 [3]. Each day 192 women die because of complications arising from unsafe abortion; that means one woman every eight minutes, nearly all of them are in developing countries. These women are likely to have had little or no money to procure safe services; many of them are young, perhaps in their teens, living in rural areas and having little social support to deal with their unplanned pregnancy [3]. Some of them have been raped, and some have experienced an accidental pregnancy due to the failure of the contraceptive method they were using or the incorrect or inconsistent way they used it. Some of them lacked knowledge about the methods used to prevent unintended pregnancy or did not have the means to obtain them. Some may have found contraceptive services hard to reach, while others may have been turned away by insensitive providers [3].

Despite the fact that different modern contraceptives exist worldwide, the problem of unintended pregnancy still exists, which could be due to gap in awareness, negative attitudes towards contraception, low accessibility or as a result of sexual assault [1].

We can understand that unwanted and unplanned pregnancy which predisposes females to unsafe abortion is a big concern. This unplanned and unwanted pregnancy could be prevented by efficient use of emergency contraception. Females who are at risk can use emergency contraception only if they have knowledge about and good attitude towards emergency contraception. Hence assessment of knowledge, attitude and practice is essential and significant in many directions [4].

Information on the knowledge, attitude and practice of university student on EC is limited in Ethiopia and other developing countries, this study aimed to assess the knowledge, attitude and practice of EC among female undergraduate students of Unity University.

\subsection{Study Design, Period and Setting}

A cross-sectional study design was conducted from February to July /2019. The study was conducted in Adama town in the South Eastern Ethiopia and one of rift valley town that forms one of special zone of Oromia regional state and capital city of East Shewa zone found at $100 \mathrm{~km}$ from Addis Ababa. Unity University is one of the leading private higher learning institutions in Ethiopia. Unity, since its establishment as a language school in 1991, has made tremendous progress to become the first privately - owned University in the country, a status granted by the ministry of education. According to the registrar's office of the college, the total number of students enrolled at the time of the study was about 1276 undergraduate students, among these about 730 were female.

\subsection{Population}

All female undergraduate students in Unity University considered as a source population. All selected female undergraduate students at Unity University College during the study period considered as study population.

\subsection{Sample Size Determination and Sampling Procedure}

Sampling size was calculated depends on our objective using single population proportion formula. The proportion (P) that obtained from the result of KAP of emergency contraceptive utilization among Ethiopian colleges and university female students in Haramaya University $(25.7 \%)$ had good knowledge [5], universities in Addis Ababa (53\%) [6] had positive attitude and Haramaya university $33.3 \%$ had used emergency contraceptive methods [5] With this 95\% CI, and $5 \%$ marginal error (where $\mathrm{n}$ is desired sample size, $\mathrm{z}$ is value of standard normal variable at $95 \% \mathrm{CI}$ which is 1.96 and $\mathrm{d}$ is a marginal error which is $5 \%$ ) (Table 1 ).

\section{Methods and Materials}

Table 1. Showing Sample size calculation assessment of knowledge, attitude and practice of emergency contraceptive among female college students in Unity University, Adama, Oromia, Ethiopia, 2019.

\begin{tabular}{llll}
\hline Variable & Proportion $(\mathbf{P})$ & Calculated sample size & Decision \\
\hline Knowledge & GoodKnowledge25.7\% & $293.422 \sim 293$ & Rejected \\
Attitude & Positive attitude-53\% & $382.78 \sim 383$ & Accepted \\
Practice & Used-33.3\% & $339.75 \sim 340$ & Rejected \\
\hline
\end{tabular}

Correction formula is used since total population is less than 10,000 , final sample size is 276 after correction and $10 \%$ no response rate.

Therefore, $\mathrm{N}=276$ (after adding 10\% contingency) female students will participate in the study.

To obtain a representative sample, stratified random sampling was applied to select study participants from the source population. First the students was divided in to five practical strata, which are Business students, management students, marketing student, accounting students, and computer science students. From each stratum, participants were selected by simple random sampling based on the proportion of the number of female students in each stratum. The total number of Business students is 64, management students are 33, marketing student are 86, accounting students are 462 , computer science students are 85 . Since number of female students in each stratum is different, it's allocated proportionally based on their number student in each strata. 
Table 2. Total number of selected female students of Unity University $1^{\text {st }}-3^{\text {rd }}$ year students in each department, 2011 EC academic year.

\begin{tabular}{lllllll}
\hline Departments & Business & Managements & Marketing & Accounting & Computer Since & TOTAL \\
\hline $1^{\text {st }}$ & 13 & 7 & 16 & 74 & 11 & 121 \\
$2^{\text {nd }}$ & 6 & 2 & 10 & 54 & 47 & 84 \\
$3^{\text {rd }}$ & 5 & 4 & 32 & 175 & 32 & 71 \\
TOTAL & 24 & 13 & & 32 & 276 \\
\hline
\end{tabular}

\subsection{Study Variables}

Dependent variables

Knowledge, attitude and practice of Emergency contraceptive

Independent variables

1) Socio demography (Age, Religion, Marital status, Family monthly income, Parents' educational status).

2) Reproductive history (sexual experience, age of first sex, reason of sexual practice, pregnancy, outcome of pregnancy).

3) Respondent Habit: (chat chewing, smoking, Alcohol drinking, Night club).

\subsection{Operational Definition}

1) Emergency contraception: is a form of modern contraception that can be used immediately after sexual intercourse but before pregnancy is established. It is intended for emergency situations such as unprotected intercourse, contraceptive failure or rape.

2) Abortion: Termination of pregnancy before the fetus reaches 28 weeks of gestation. Termination of pregnancy before the fetus reaches 28 week.

3) Unsafe abortion: Abortion often conducted by lay people in non-sterile condition.

4) Student who score above mean consider as had good knowledge below the mean consider as Poor Knowledge [7].

5) Student who score above mean determined as Positive Attitude and student who score below the mean consider as poor Attitude [7].

6) Unintended pregnancy: pregnancy occurred with no plan.

7) Practice: Any previous history of EC usage [7].

\subsection{Data Collection Tool and Procedure}

Data was collected by using self- administer Question which is prepared in English language to assess socioeconomic status, reproductive characteristics as well as their knowledge, attitude and practice towards emergency contraception. Most of the questions are adapted from previously conducted studies at Arsi University [8] among female students with some modification based on the local context. The questionnaires is prepared by English, because it is universal language and with the assumption of fair communication by this educational level. Likewise, confidentiality and anonymity of the study was reassured. The data was collected while students were in class rooms. The data collectors were two female diploma nurses and one supervisor who have a first degree in nursing. Training were given for data collectors and supervisor before the pretest on the objective of the study, the contents of the questionnaire, issue related to the confidentiality of the response and the right of the respondents for one day.

\subsection{Data Quality Management}

To assure the quality of the data, properly designed data collection tool was prepared, before the actual data collection, the prepared questionnaire was pre tested on students who are not included in the study to verify clarity of instruments. $10 \%$ Pretest was done at Rift Valley University. This was helping us to modify some of the questionnaires based on their possible answer after clear discussion. After the questionnaires were gathered and checked for completeness by the principal investigators. To control the quality of data for analysis, editing data before entry, data checking, cleaning, and missing value analysis was done.

\subsection{Data Processes and Analysis}

The filled questionnaires were checked for completeness, cleaned manually and entered in to Epi Info version 7 then the analysis was done using SPSS version 20 statistical packages for analysis. Different forms of analysis like descriptive statistics, cross tabulation and logistic regression were applied to present the results. The respondent's knowledge scores were aggregated and ranged from1-8. Based on the cumulative score respondents who scored 4 (mean score) and above were considered to have "good knowledge", while those who scored below the mean score were considered to have "poor knowledge". Practice was determined based on every use of EC after exposure to unprotected sexual intercourse to prevent unintended pregnancy. To summarized level of Attitude questions were calculated after a number of questions were presented. Attitude about ECPs was determined by using 3 multiple-choice questions. Each correct answer corresponded to 2 point score will adopted, and so there is a total of 6 points for the three questions. Based on the cumulative score respondents who scored 3 (mean score) and above were considered to have "positive Attitude", while those who scored below the mean score were considered to have "poor Attitude".

\subsection{Ethical Consideration}

Ethical clearance was obtained from Adama General Hospital and Medical College ethical review board The purpose of the study was explained to all study participants; they was also informed that all of their responses are confidential and anonymous, and they have all the right not to be involved in the study or not to answer any of the questions. 


\section{Result}

\subsection{Socio Demographic Characteristics of Participants}

A total respondent 276 were participated in the study which gives $100 \%$ response rate. Among 276 study participants 259 (93.8) of them are within the age category of
15-24 and 17 (6.2) of them are within the age category of 2529. More than half $231(54.3 \%)$ of the respondents were followers of the Orthodox Christianity. $231(83.7 \%)$ of the respondents were single. Most of the respondents $272(58.4 \%)$ came from urban area. Regarding income among participant family 26\% had monthly income 700-1500 ETB (Table 1).

Table 3. Socio demographic characteristics of undergraduate female students of unity university, Ethiopia, July, 2019 (n=276).

\begin{tabular}{|c|c|c|c|c|}
\hline $\mathrm{Sr}$ & Variable & & Frequency & Percentage \\
\hline \multirow{2}{*}{1} & \multirow{2}{*}{ Age } & $15-24$ & 259 & 93.8 \\
\hline & & $25-29$ & 17 & 6.2 \\
\hline \multirow{4}{*}{2} & \multirow{4}{*}{ Religion } & Orthodox & 150 & 54.3 \\
\hline & & Catholic & 10 & 3.6 \\
\hline & & Protestant & 54 & 19.6 \\
\hline & & *Other & 7 & 2.5 \\
\hline \multirow{3}{*}{3} & \multirow{3}{*}{ Marital states } & Married & 31 & 11.2 \\
\hline & & Divorced & 2 & 0.7 \\
\hline & & Separated & 12 & 4.3 \\
\hline \multirow{2}{*}{4} & \multirow{2}{*}{ Residence } & Urban & 185 & 67.0 \\
\hline & & Rural & 91 & 33.0 \\
\hline \multirow{3}{*}{5} & \multirow{3}{*}{ Respondents year of study } & First year & 112 & 40.9 \\
\hline & & Second year & 107 & 37.1 \\
\hline & & Third year & 53 & 19.3 \\
\hline \multirow{4}{*}{6} & \multirow{4}{*}{ Father occupation } & Farmer & 36 & 13.0 \\
\hline & & Gov't employee & 93 & 33.7 \\
\hline & & Merchant & 77 & 27.9 \\
\hline & & $* *$ Other & 70 & 25.4 \\
\hline \multirow{4}{*}{7} & \multirow{4}{*}{ Mather occupation } & Housewife & 158 & $57.8 \%$ \\
\hline & & Gov't employee & 31 & 11.2 \\
\hline & & Merchant & 47 & 17.2 \\
\hline & & Farmer & 13 & 4.4 \\
\hline \multirow{4}{*}{8} & \multirow{4}{*}{ Parent educational level } & Illiterate & 13 & 4.7 \\
\hline & & Elementary & 61 & 22.1 \\
\hline & & Secondary & 73 & 26.4 \\
\hline & & College and above & 129 & 46.7 \\
\hline \multirow{3}{*}{9} & \multirow{3}{*}{ Family income } & $<700$ & 65 & 26.0 \\
\hline & & $700-1500$ & 67 & 26.8 \\
\hline & & $1500-3000$ & 56 & 22.4 \\
\hline \multirow{4}{*}{10} & \multirow{4}{*}{ Respondent's Habit } & Smoking & 6 & 2.2 \\
\hline & & Alcohol drinking & 14 & 5.1 \\
\hline & & Night club & 24 & 8.8 \\
\hline & & None of these & 223 & 81.4 \\
\hline
\end{tabular}

Note; *other: wakefeta, Jova...** daily labor, Doctor...

\subsection{Reproductive History of Respondents}

From total of 276 of respondents, the majority of them 119 (71.7\%) have not ever practice sexual intercourse. of those respondents having sexual experience, about 76 (28.3\%) have the first sexual intercourse at age between 16-24, 55 (76.5\%). $22(29.3 \%)$ students had an experience of pregnancy at least once and majority, 10 (43.5\%) of the pregnancies were unwanted. Around $4(30.8 \%)$ respondents reason fail to prevent the pregnancy is forget to take pills, out of this 9 (50\%) pregnancy was induced abortion. $157(57.7 \%)$ of respondents had communication about reproductive issues with family $73(46.5 \%)$, peers $61(38.9 \%)$, and health professional $23(14.6 \%)$.

Table 4. Reproductive characteristics of female undergraduate students of Unity University, Ethiopia, July2019 ( $n=276)$.

\begin{tabular}{|c|c|c|c|c|}
\hline $\mathrm{Sr}$ & Variable & & frequency & Percentage \\
\hline \multirow{4}{*}{1} & \multirow{4}{*}{ If women has regular menstrual cycle } & During the menstrual flow & 21 & 7.7 \\
\hline & & The first week of ministerial cycle & 41 & 15.0 \\
\hline & & The second and third of menses & 101 & 37.0 \\
\hline & & I don't know & 110 & 40.3 \\
\hline
\end{tabular}




\begin{tabular}{|c|c|c|c|c|}
\hline $\mathrm{Sr}$ & Variable & & frequency & Percentage \\
\hline \multirow{2}{*}{2} & \multirow{2}{*}{ Respondent sexual experience } & Yes & 76 & 28.3 \\
\hline & & No & 198 & 71.7 \\
\hline \multirow{2}{*}{3} & \multirow{2}{*}{ First age of sexual intercourse } & $16-24$ & 57 & 76.4 \\
\hline & & $25-30$ & 19 & 23.6 \\
\hline \multirow{6}{*}{4} & \multirow{6}{*}{ Reason for sexual practice } & Marriage & 24 & 32.4 \\
\hline & & Forced sex & 42 & 15.2 \\
\hline & & Rape & 2 & 2.7 \\
\hline & & Love & 42 & 56.8 \\
\hline & & To get some advantage from partner & 3 & 4.1 \\
\hline & & To get mark/grade & 3 & 4.1 \\
\hline \multirow{3}{*}{5} & \multirow{2}{*}{ Occurred pregnancy } & Yes & 23 & 29.3 \\
\hline & & No & 53 & 70.7 \\
\hline & \multirow{4}{*}{ If yes how many times } & One & 17 & 73.9 \\
\hline \multirow{3}{*}{6} & & Two & 5 & 21.7 \\
\hline & & Three & 1 & 4.3 \\
\hline & & More than three & 0 & 0 \\
\hline \multirow{2}{*}{7} & \multirow{2}{*}{ First age of pregnancy } & $18-22$ & 17 & 73.8 \\
\hline & & $23-25$ & 6 & 26.0 \\
\hline \multirow{2}{*}{8} & \multirow{2}{*}{ Was your pregnancy wanted } & Yes & 13 & 36.5 \\
\hline & & No & 10 & 43.5 \\
\hline \multirow{2}{*}{9} & \multirow{2}{*}{ Outcome of the pregnancy } & Child birth & 9 & 50.0 \\
\hline & & Induced abortion & 9 & 50.0 \\
\hline \multirow{4}{*}{10} & \multirow{4}{*}{ If Induced abortion where did you it performed } & Public health facilities & 5 & 41.7 \\
\hline & & Private clinic & 4 & 33.9 \\
\hline & & Traditional abortionist & 1 & 8.3 \\
\hline & & Other & 2 & 16.7 \\
\hline \multirow{2}{*}{11} & \multirow{2}{*}{ Had communicant about reproductive issues } & Yes & 157 & 57.7 \\
\hline & & No & 115 & 42.3 \\
\hline \multirow{3}{*}{12} & \multirow{3}{*}{ If yes With whom } & With family & 73 & 46.5 \\
\hline & & With peers & 61 & 38.9 \\
\hline & & With health professional & 23 & 14.6 \\
\hline
\end{tabular}

\subsection{Students' Knowledge of Emergency Contraceptives}

Of the total participants, $202(73.7 \%)$, ever heard about any contraceptive method; the sources of information were mass media $125(60.1 \%)$, peers/friends $4(1.9 \%)$, schools club 7 (3.4\%), and health workers $32(75.5 \%)$. Among female students who heard about EC 147 (53.8\%), only 135 $(84.9 \%)$ correctly identified time of administration of the method, from this $80(29.5 \%)$ mentioned oral pills, and 24 (15.1\%) mentioned IUCD.

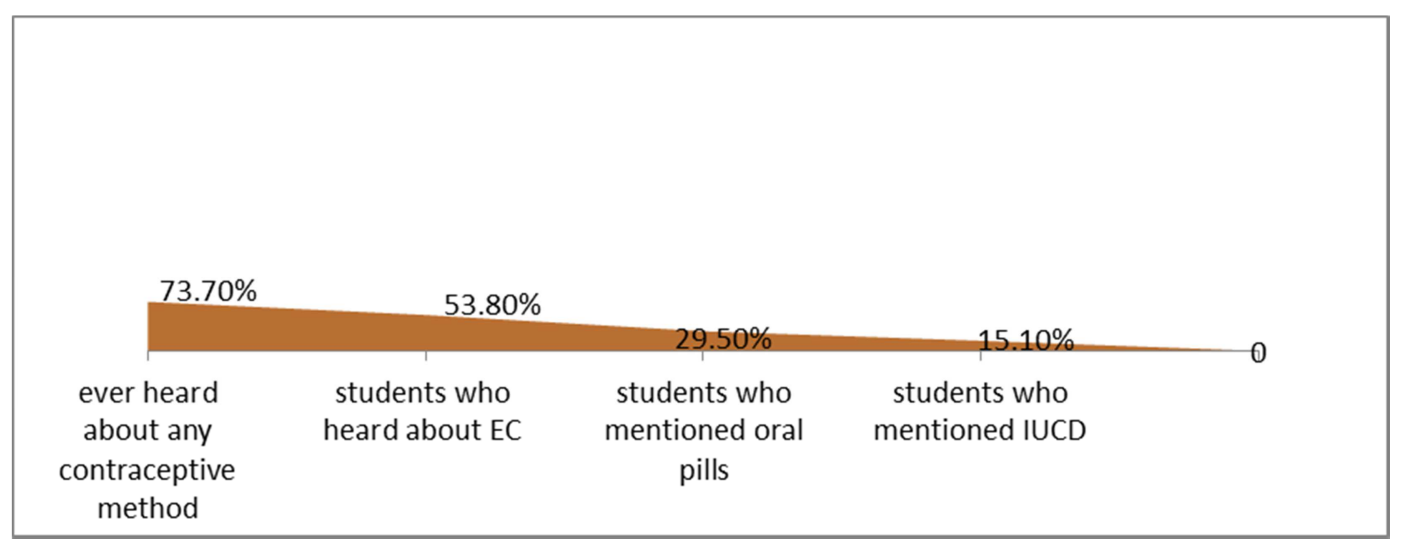

Figure 1. Knowledge towards EC among female undergraduate students of Unity University, Ethiopia, July 2019 (n=276).

Regarding situations of EC taken, majority of those aware of EC $56(34.8 \%)$ mentioned that EC indicated after unprotected sexual intercourse, $18(11.2 \%)$ when forced sex, $18(11.2 \%)$ use as a backup when condom breaks and 8 $(5.0 \%)$ thought it is important when oral contraceptive pill
(OCP) is forgotten Most of 14 (26\%) from health institution, $36(67.9 \%)$ pharmacy, could get this method. And the recommended time between the dose $20(12.4 \%)$ identified as 72 hours apart and 59 (36.6\%) were side I do not know. 


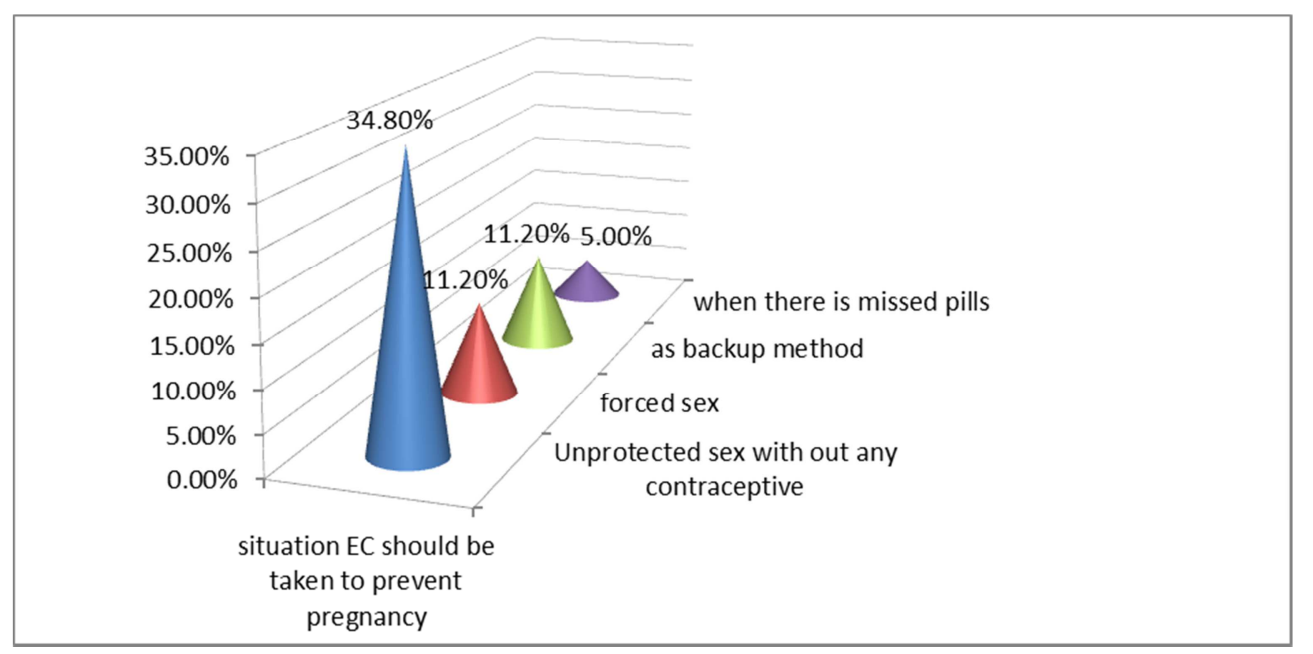

Figure 2. Knowledge towards EC among female undergraduate students of Unity University, Ethiopia, July2019 (n=276).

The overall summary index for knowledge disclosed that $159(72.4 \%)$ of the study participants had god knowledge. Above half of the respondents $(57.2 \%)$ could identify the correct timing for administration of EC pills. However, only $2(2.9 \%)$ could tell the correct timing of insertion of IUCD.

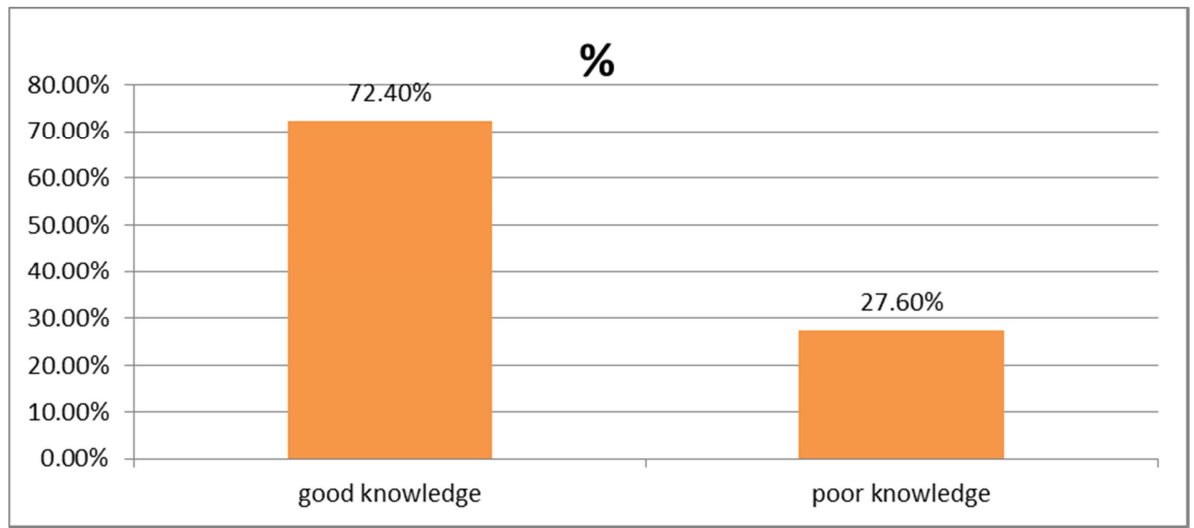

Figure 3. Level of Knowledge towards EC among female undergraduate students of Unity University, Ethiopia, July2019 (n=276).

\subsection{Attitudes Towards EC}

With regard to, majority of the respondents $99(44.9 \%)$ believes that EC may increase risky behavior. Concerning the overall level of female students' attitudes, more than half189 (69.7\%) of them had positive attitude towards EC.

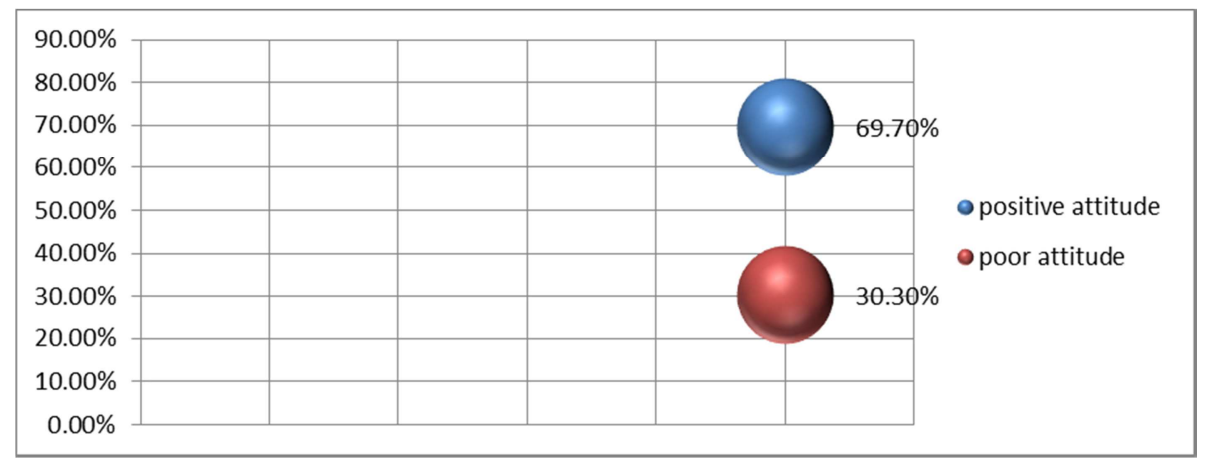

Figure 4. Attitudes towards EC among female undergraduate students of Unity University, Ethiopia, July2019 (n=276).

\subsection{Practice of Emergency Contraceptive (EC)}

Out of the study participants 75 (27.5\%) were experienced sexual intercourse, out of them 55 (20.4\%) were used EC. From those $50(87.7 \%)$ used oral pills after unprotected sexual intercourse within 72 hours, None of the women had ever used Intra Uterine Contraceptive Device (IUCD). 


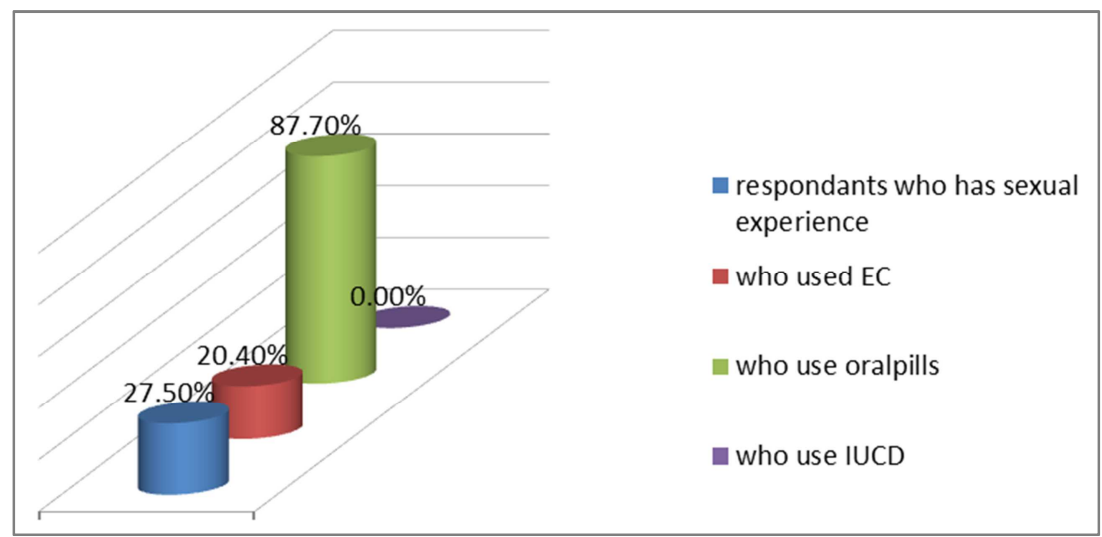

Figure 5. Practice towards EC among female undergraduate students of Unity University, Ethiopia, July 2019 (n=276).

\section{Discussion}

In this study, Above three quarters $(72.4 \%)$ of the respondents had good knowledge of $\mathrm{EC}$, which is greater to the result obtained in the studies conducted among Ethiopian colleges and university female students in Haramaya (25.7\%) [5], Arbaminch (21.9\%) [9], Addis Ababa (43\%) [6] and Arsi University 228 (27.4\%) [8]. This difference is could be due to the presents of high health promotion due to youth centers and reproductive health clubs found in our study area.

Majority of students had positive attitude towards EC 189 $(69.7 \%)$. This finding is slightly similar with the study conducted in college student in Asella town 548 (65.8\%) [10], Adama University 62.9\% [11] but greater than Study conducted in Arbaminch University 50.1\% [9], universities in Addis Ababa 53\% [6]. This discrepancy may be due to, most of the time University students are come over from different community and rural dwellers while in our study area majority of the respondents are from urban and same community so they can get access to get more information about reproductive health as well as discuss about different method of family planning.

About $55(20.4 \%)$ of the respondents had ever used emergency contraceptive. This result is greater than the study conducted in Arbaminch 2.7\% [9], universities in Addis Ababa 4.9\% [6], India 17\% [12], this finding is lower than study reported in Tanzania Donmo University 40\% [13], Mizan Tepi University 46.3\% [14] and female students in fiche town $34.4 \%$ [15]. This discrepancy may be related to misconception toward the use of emergency contraception between the communities could be the reason for the observed differences, a fear of being embarrassed during purchasing and religious beliefs can be the main reasons for not using contraception.

\section{Conclusion}

Although overall awareness of Emergency contraceptive was very high [73.7\%] among female students, Use of Emergency contraceptive among female undergraduate students was low [20.4\%]. Majority of respondents had good knowledge [72.4\%] of Emergency contraceptive and a positive attitude [69.7\%] towards using Emergency contraceptive. Strengthening information, education and communication in university or colleges on sexual reproductive health, with special emphasis on different family-planning methods (including emergency contraception) will be a problem-solving procedure for female students.

\section{Conflict of Interest}

The authors declared that they have no any competing interests.

\section{Acknowledgements}

We would like to acknowledge Adama general hospital and medical college, department of nursing, Unity University, data collectors, supervisor, study participants, family members and colleagues for their support.

\section{References}

[1] Fatuma A, Ahamed K. Assessing Knowledge attitude and practice of emergency contraception a cross sectional study among Ethiopian undergraduate female students in Adis Ababa Ethiopia. BMC Public health; 2012, 12: 110.

[2] Solomon Abrha et al. Assessment of Knowledge, Attitude and Practice among Regular Female Preparatory School Students towards Emergency Contraceptives in Mekelle, Northern Ethiopia. IJPSR. 2014. 856-864.

[3] Central Statistical Agency, Addis Ababa, Ethiopia and ICF International Calverton, Maryland, USA. Ethiopia Demographic and Health Survey 2016.

[4] Bobby K, Julia B. Knowledge attitude and practice of Emergency contraception among female students at the University of Botswana. African journal of primary health care and family medicine. 2018. 10 (1).

[5] Kirubel M, Abebaw D, Solmon A. Assessment of Knowledge, practice towards Emergency Contraception among Ethiopian female college students. International Journal of Reproductive Medicine; Volume 2019. 
[6] Wegene T, Fikre E. Knowledge, attitude and practice on Emergency Contraceptives among female students at higher educations in Addis Ababa. Ethiop J Health Dev., 2005; 21 (2): $111-116$.

[7] Anteneh Dangachew. Assessment of knowledge Attitude and Practice use among female student in Harar Preparatory school. Reproductive system and Disorders; 2017, 6 (4): 215.

[8] Faye Dadi, Hawa Abu, Fikadu Bayisa et al. Assessment of Knowledge, Attitude and Practice of Emergency Contraception among female students of Arsi University, college of Health Science; 2017.

[9] Alemitu W. Knowledge, attitude and practice on Emergency Contraceptive among female students in Arbaminch. Ethiop. j. health dev. 2011; 25 (3). 176-183.

[10] Seifu Mengistu. Assessment of level of awareness and utilization of emergency contraception among college female students in Asella town, Arsi Zone, Oromia Regional state, South-East Ethiopia, June 2007 (Unpublished Master thesis).

[11] Tilahun D, Assefa T, Belachew T. (2010). Knowledge, attitude and practice of emergency contraceptive among Adama university female students. Ethiop. J health sci., 2010: 20 (3). 195-202.

[12] Baba S, Ashwini K. Knowledge attitude and practice of contraception among college students in Sikkim India. Journal of the Turkish German Gynecology Association; 2010, 11 (2): 78-81.

[13] Kara w, Benedicto M. Assessment of Knowledge, Attitude and Practice of Emergency Contraception methods among Female Undergraduate in Domoa, Tanzania. International Journal of Reproductive Medicine; 2019 (8).

[14] Bisrat Zeleke, Bosena Tebeje, Fekadu Yadasa. Factors associated with utilization of emergency contraception among female students in Mezi Tepi University, south west, Ethiopia. BMC res notes, 2015; 8: 817.

[15] Abebe Feyisa. Assessment of knowledge, attitude and practice Towards Emergency Contraceptive among female students in Abdisa Aga High school, Fiche Town, Northern, Ethiopia. International Journal of Chinese Medicine, 2016; 1 (1): 16-23. 